This is a reviewed article

\title{
(Im)politeness between copy-editors and translators: Working from different islands?
}




\section{Abstract}

This article addresses the nature of the interaction between translators and copy-editors in the process preceding the publication of literary translations in Norway. The copy-editing of translations is here understood as a potentially face-threatening act. The aim of the article is to take copy-editors' politeness strategies and translators' experiences with impoliteness and relate them to the professional role of copy-editors. The material for the study consists of nine translation drafts with copy-editors' comments and changes, and 14 semi-structured qualitative interviews with copy-editors, translators and publishing editors. The study employs quantitative and qualitative analyses and compares data from the translation drafts, described in positive terms by those who produced it, with accounts of negative experiences from the copy-editing process, as accounted for in the qualitative interviews. I argue that both copy-editors and translators are well aware of the potential for conflict in the copy-editing process. Experienced copy-editors therefore tend to be very polite, which can be regarded as an aspect of their acquired communicative competence. I also argue that some of the negative experiences of copy-editors and translators may be linked to the overall low degree of professionalization of Norwegian copy-editors as an occupational group. 


\section{Introduction}

Most literary translations pass through the hands of one or more professionals responsible for quality assurance in the target language publishing process. In the Norwegian context, the stylistic and content-oriented revision of translations is usually the task of a freelance copyeditor. The more purely linguistic and technical reading of the target text, looking for objective errors of grammar, spelling and formatting, is the task of a proofreader. ${ }^{1}$

Based on material from the Norwegian publishing context, and combining quantitative and qualitative analysis, this article examines copy-editing as an inherently face-threatening act, one in which one of the parties (the translator) risks feeling offended while the other party (the copy-editor) risks feeling embarrassed, since the procedure involves detecting perceived shortcomings and introducing perceived improvements. By contrasting material related to positive and negative experiences, the aim of the article is to relate politeness (i.e. strategies aimed at redressing the face threat) and impoliteness (i.e. speech acts that cause offence) to the copy-editor's professionalism.

The material consists of a combination of naturally occurring and researcher-generated data: nine translation manuscripts with comments from the editing process, and 14 qualitative interviews with practitioners. The manuscripts were handed over to me by the translators (or, in a few cases, by the copy-editors or publishers), and all parties gave me permission to use them. This material was taken from a larger set of 16 translated books and approximately 40 qualitative interviews that I collected in 2013-2015 as part of a larger bottom-up study of the role of the copy-editor in literary translation in Norway.

During the collection of the textual material, it became apparent that most translators, copyeditors and publishing editors were most comfortable with giving me access to translation drafts from processes that they could describe in positive terms, that is, processes where the copy-editors and translators had been happy with each other's work. For ethical reasons, I also actively encouraged the informants not to hand over any material to me that could negatively affect their relationship with other professionals in the future. The nine edited translation drafts were selected from a set of 16 edited texts according to three criteria: they were all done in electronic format; they were translations from either English or a Romance language; and the professionals involved deemed the work to be relatively good practice, both in terms of the translation and the copy-editing, and with a low level of conflict (or no conflict whatsoever). Likewise, the 14 interviews were selected from the larger set of interviews based on two criteria: the interviewees had either been involved in producing the textual material or that they were especially eloquent on themes relating to (im)politeness. The nine interviews were transcribed and selectively coded (Braun \& Clarke, 2013, p. 206), that is, the instances in which the phenomenon I was interested in, (im)politeness and positive and negative experiences, were identified.

In the interviews, the translators and editors were invited to discuss the professional role of the agents involved in the creation of literary translation. All the professionals who handed textual material over to me were invited to an interview, but not all of them could. Some interviews were also conducted with professionals who were not directly involved with the textual material. Since the textual material was mostly described in positive terms, the interviews allowed the informants to discuss negative experiences.

\footnotetext{
${ }^{1}$ My use of the terms copy-editor/copy-editing and proofreader/proofreading is consistent with the terms used by the British Society for Editors and Proofreaders (SfEP). They are the closest equivalents of the two Norwegian terms språkvasker (or manusvasker) and korrekturleser; see

http://www.sfep.org.uk/about/faqs/what-is-the-difference-between-copy-editing-and-proofreading.
} 


\section{Background}

\section{Literary translation and the publishing process}

The publishing process of literary translations cannot be understood without referring to the legal system in which such books are produced. In the 172 countries, including Norway, that adhere to the Berne Convention, which was adopted in $1886,{ }^{2}$ literary translations are the intellectual property of their authors, that is, both the source language author and the translator. In other words, legally speaking, translators are authors of the target text, for which they hold exactly the same kinds of copy-rights as source language authors of their text. ${ }^{3}$ When a publishing house acquires the rights to the published edition of an author's intellectual property, it does so by means of a contract that specifies how many times, where and in what sorts of publications (paper book, e-book, audio book, etc.) a given work may be used by the publisher. At the same time, publications and backlists are an important part of the identity and reputation of publishing houses. Publishers have an interest and responsibility in ensuring that the book is as good as possible, for the sake of the author and the readers, and to ensure positive reviews, sales, etc. Therefore, they are also motivated to assure the quality of the works they publish. The publisher may easily be perceived as a constraint (Lefevere, 1992, p. 12) that limits the decision-making power of the translator. This does not cover the whole picture: translators also expect publishers to provide a proper quality assurance of their translation. We can see this for example from item 5.1 in the Norwegian standard contract between publishers and translators, which states that the publisher has an obligation to the translator to assure that the text is read and edited in accordance with "good publishing practice". In other words, it is a part of the publisher's responsibility to offer resistance and assistance.

The fact that authors of original publications do not work in a vacuum has been widely discussed ever since the complexity of the author concept was made evident in Foucault's (1998) seminal article on the author function, originally published in 1969. Authorship and the interaction between the author and other agents has been thoroughly discussed (see e.g. Darnton, 1982; Love, 2002; McGann, 1992; Stillinger, 1991). In translation studies, the term "multiple translatorship" (Jansen \& Wegener, 2013) has been coined to account for the collaborative nature of many, if not most, translated works.

\section{Translation editors in Norway}

In Norway, two terms are typically used for the quality assurance of translated fiction: one is vask (lit. 'cleaning, washing'), with the sprakvask ('language cleaning') and manusvask ('manuscript cleaning') variations. The other is korrektur (from the German word Korrektur, derived from the Latin correctura 'improvement'). As mentioned earlier, I refer to these readings as copy-editing and proofreading, respectively, in English. The professionals carrying out these two tasks are referred to in the publishing process as holding the roles of vasker ('cleaner'), alternatively manusvasker or språkvasker ('manuscript cleaner' or 'language cleaner'), and korrekturleser (korrektur-'reader'), that is, copy-editor and proofreader, respectively.

Copy-editing is the first round of editing the text, and it involves a stylistic and contentoriented revision whereby the relation between the source text (original) and the target text (what is generally referred to as "the translation") is taken into account. The copy-editor complements and checks the role of the translator. The manuscript is then returned to the translator, who then goes through the copy-editing, changes his or her text accordingly

\footnotetext{
2 http://www.wipo.int/treaties/en/ShowResults.jsp?treaty id $=15$

3 see Ceatl.eu: Why literary translators are authors

https://www.ceatl.eu/translators-rights/legal-status
} 
(accepting, rejecting or finding new solutions to points in comments) and sends it back to a publishing editor (broadly referred to in Norway as a redaktør, which literally means editor, although, in practice, not all editors edit the text). The text is then forwarded for proofreading, a more technical reading aimed at spotting problems perceived as objective errors, including orthographic issues, punctuation and formatting. Proofreading and the proofreader will only briefly be touched upon in this article, as the proofreader is not usually expected to compare the translation to the source text and thus, at least in principle, does not complement the role of the translator to the same extent as the copy-editor. In practice, however, the boundaries between copy-editing and proofreading are blurry, as I will address below.

The translation may also be edited by the publishing editor. In fact, the copy-editor may be seen as a freelancer who does a job that would, at least traditionally, be understood as that of the publishing editor, hence the term publishing editor (or, in Norwegian, redaktør). In a minority of Norwegian publishing houses, it is common practice that the publishing editor edits/proofreads the whole text. Most frequently, the copy-editor and the proofreader(s) will be freelancers, like the translator, hired by the publishing editor, who supervises and coordinates the work of the translator and the copy-editor. The copy-editor and the proofreader are almost always two distinct individuals, as this ensures that they have a "fresh eye" on the text. ${ }^{4}$

Even though there are similarities between the professional situation of translators and copyeditors/proofreaders in the sense that both parties are freelancers working for publishing houses, there is a clear asymmetry in terms of professionalization as far as the Norwegian publishing context is concerned. In general, it may be argued that translators do not hold all the traits needed to be characterized as a full profession, such as (according to the strict interpretation of trait models) recognized training programmes, codes of ethics, certification systems and professional associations (Dam \& Koskinen, 2016; Fauske, 2013). That professionalization is related to education is also emphasized by Molander and Terum (2013) and Skaaden (2013). It is not necessary to be trained as a translator or a copy-editor in order to enter these occupations in Norway. Before becoming a profession an occupational group must undergo a process of professionalization (see Skaaden 2013, p. 217, who quotes Parsons 1968, and Dam and Koskinen 2016). Both literary translators and copy-editors are identifiable occupational groups in the Norwegian publishing context, but they have different levels of professionalization. The gap between the two groups, in terms of organization and power, is significant. Norwegian literary translators have two exceptionally strong associations: the Norwegian Association of Literary Translators (NO) and the Norwegian Nonfiction Writers and Translators Association (NFF). Since translators hold copyrights and are recognized as authors and artists according to Norwegian legislation, they collectively administer money from the reproduction rights organization Kopinor and a public lending right remuneration from a collective library agreement. Both forms of remuneration are distributed to the members in the form of grants, and they empower the associations with the economic means to promote their members' interests. The strength of the two Norwegian literary translators' associations became evident in 2006 when they joined forces against the Norwegian Publishers' Association and organized a campaign to improve their working conditions, a campaign that eventually culminated in the aforementioned standard contract with a standard rate, which is binding for members of the signatory translator and publisher associations. Copy-editors have no collective income, and as of 2016, the Norwegian Copyeditors' Association (Norsk forening for språkkonsulenter) seems to have been shut down and reappeared as a closed Facebook group (in 2014, when the interviews for this study were conducted, the association did have a web page). Copy-editors have no standard contract with publishers, and their rates vary much more than those of literary translators. The literary translators' associations have web pages that offer information about the profession, and they

\footnotetext{
${ }^{4}$ That the translation should be copy-edited and proofread by two different people is also recommended in the Norwegian Association of Literary Translators' booklet Manusvask i praksis (Copy-editing in practice), as discussed below.
} 
compile statistical information about their members' income levels, working conditions, etc. However, there are no available studies on the living and working conditions of Norwegian copy-editors. Several Norwegian universities, including NTNU in Trondheim, the University of Oslo and the University of Agder, offer courses in translation or translation studies, although there are no schools or private academies that offer courses in copy-editing.

\section{Material and Methodology}

As briefly mentioned in the introduction, this study draws on two sets of material: manuscripts and interviews. Both sets were collected in 2013 and 2014 and relate to copy-editing and editor-translator interaction. Prior to the collection of the material, the project was submitted to the Norwegian Centre for Research Data (NSD) and was approved by a research ethics committee. Since the material involves the improvement of textual weaknesses, including errors, it has been anonymized. The real names of the publishing houses, publishing editors, copy-editors, proofreaders and translators, as well as the authors of the source language books, have therefore been withheld. The interviewees are referred to by pseudonyms and books by language and a number.

The translations in the material are either from English or a Romance language. In the latter case, the language has not been further specified due to considerations of anonymity, as there are only a limited number of active literary translators of each Romance language into Norwegian. The two language groups were chosen to account for two different linguistic realities. A large number of translations into Norwegian are from English. ${ }^{5}$ With this language combination, most copy-editors can be expected to understand the source language and are able to compare this to the source text. However, even from large Romance languages, such as French or Spanish, it may be difficult for publishing editors to find a copy-editor with knowledge of the source language. ${ }^{6}$

The translations were published between 2008 and 2014, and none of the agents involved knew that their work would later become part of this study. The translators, copy-editors, publishing editors and (to a limited extent) proofreaders granted me permission to use the material after the book was published or ready for publication. The material thus represents naturally occurring data.

Of the nine copy-edited translation drafts in the material, five are from English (ENG1, ENG2, ENG3, ENG4 and ENG5) and four from Romance languages (ROM1, ROM2, ROM3a and ROM3b). The nine translators and the nine copy-editors who worked with the texts are all freelancers. ROM3a and ROM3b differ from the other seven in that they have the same translator, copy-editor and publisher, and the books are also by the same author.

As explained, the textual material is mainly "low conflict" material that I describe as "good practice". The material does not reflect the conflicts or feelings of frustration that may sometimes arise in the editing process. Naturally occurring material reflecting such conflicts is probably difficult to obtain. In fact, Buzelin (2007, p. 142) proposes that the fact that editing processes in translations may entail conflict could be one reason why relatively few studies have been dedicated to the editorial process that translations go through prior to publication. To compensate for this, I draw on interview material to account for more problematic aspects. The interview material involves elicited responses, as the interviewees were invited to recall negative experiences. However, most interviewees were generally eager to talk about both the positive and negative aspects of their work, not least the copy-editors,

\footnotetext{
${ }^{5}$ According to figures from Bokbasen AS (personal communication, September 1, 2017), a company that provides metadata concerning the Norwegian publishing sector, 5,409 translated fiction titles were published in Norway between 2011 and 2016. In 830 of these, the source language was not specified. Out of the remaining 4,579 titles, $2,781(61 \%)$ were translations from English, approximately 250 titles (5.5\%) from French, 58 titles $(1 \%)$ from Spanish, 40 titles from Italian (1\%) and $25(0.5 \%)$ from Portuguese.

${ }^{6}$ This was also confirmed in the interviews with the publishing editors, such as Marie and Robert, who will be quoted later on in this study.
} 
most of whom perceived that their largely invisible work was granted little attention. Many were therefore thankful for the invitation to talk about their work and, following the interview, expressed that they had enjoyed talking about it.

Prior to the interviews, the interviewees received an interview guide that they were encouraged to review for inspiration, even though the interviews did not follow a strict reading of the interview guide. In the interviews, the interviewees were invited to discuss the role of copy-editors, translators and proofreaders in terms of how these roles are in practice and how they ought to be and should not be (and the possible consequences in that case). Most interviewees could recall negative experiences relating to the translation and editing processes, some of which were recounted in this article. The interviews were recorded in 2014 and were subsequently transcribed, content-tagged and qualitatively analysed. Some features of the oral discourse that were not relevant for the purpose of the study, such as fillers, repairing and false starts, have been omitted from the transcriptions, as quoted in this article. Any information that might have compromised anyone's anonymity has also been omitted. I translated both the interview quotes and quotes from the textual material included in this article, and for the sake of anonymity, no mention was made of the original phrasing.

The nine copy-edited translation drafts were examined quantitatively: first, the number of words that the copy-editor had edited with Word's tracked changes activated in the draft that they received from the translator was calculated for each document, based on Word's automatic count of edited characters (the number of characters deleted by the copy-editor was added to the number of characters inserted by the copy-editor; this figure was divided by two and subsequently divided by the average number of characters per word in the book). The model makes no adjustments for the fact that some changes automatically generate other changes (e.g. in Norwegian, adjectives agree in gender and number with nouns, thus, a noun change may entail a changed adjective), but as the model is the same for all books, it serves as a basis for comparison. The average number of words changed in the text was then expressed as an average number per standard page of 2,000 characters in each book.

Second, the number of comments that the copy-editors made in each document was counted and expressed as an average number distributed on the standard pages of the text. The comments may have referred to the same sort of changes as the tracked changes, only that they represent a less invasive way of editing, making suggestions in a box rather than making direct changes to the translator's text. The comments were then categorized in terms of the directness of the request: strong suggestion, explanation and weak suggestion (for examples, see the analysis). The three categories are regarded as different forms of politeness strategies, which are moves that are recognizably oriented towards redressing affronts to the translator's face (Kádár \& Haugh, 2013, p. 26). In some texts, there was also some translatorcopy-editor dialogue, meaning that the translator had inserted questions into the draft, soliciting the copy-editor's review and opinion. Further, in two of the documents, there were comments dedicated exclusively to praising the translator's work or to talk that was not related to the copy-editing process.

\section{Copy-editing and (Im)politeness}

Editing texts presupposes a potential for disagreement, tension and frustration, as different professionals working on the same text will inevitably have differing points of view. As noted earlier, the copy-editor is even supposed to offer some resistance. In literary translation, the potential object of disagreement covers such diverse aspects as the interpretation of the source text, aesthetical preferences, the (re-)construction of literary characters and voices and the norms governing the target language.

A central concept in theories of politeness and impoliteness is the concept of face. The term can be traced back to the American sociologist Goffman (1967) and is related to the notion of the social self or, in more popular terms, one's "image". Face damage may have emotional 
consequences such as embarrassment and hurt feelings (Culpeper, 2011, p. 90; Goffman, 1967). Recent research further stresses the inseparability of (im)politeness and emotions (Culpeper, 2011, pp. 48-69; Kádár \& Haugh, 2013, pp. 207-231). While translators know that the copy-editors' editing of their text is a form of resistance that they should expect and welcome, they will still receive the copy-editors' comments textually, that is, they are not accompanied by the body language or prosody that usually accompanies spoken utterances. To a great extent, they may therefore have to infer the intensity of the copy-editor's evaluations, something that may, of course, render unforeseeable results. The same applies to the copy-editor if he or she receives written comments or instructions from the translator. Politeness involves limiting the potential face threat to the addressee, that is, making sure that he or she is not offended. If an utterance causes severe face damage, it may be described as offensive or impolite. In classical politeness theory developed by Brown and Levinson (1987), the authors distinguish between "positive face", understood as the desire of all humans for approval, and "negative face", understood as the desire not to be imposed upon in our actions. More recently, Spencer-Oatey (2002) proposed a distinction between quality face and social identity face (p. 540; Culpeper, 2011, p. 29). The first applies to our fundamental desire to be positively evaluated for our personal qualities, while the latter speaks to our desire to be evaluated positively in social identities and roles, including our job. The present study explores the potential threat to the social identity face of the professionals involved.

According to Brown and Levinson (1987), some speech acts are inherently face threatening. Taking into account that it is the copy-editor's task to improve the translator's work (which could be perceived as invasive if done impolitely) and offer criticism, the copy-editing process may indeed be interpreted as inherently face threatening, both in terms of positive and negative face. Even though the copy-editor most likely sits alone when working on the text, without the translator being physically present, it is reasonable to assume that copy-editors will employ some politeness strategies when addressing translators so as to avoid conflict or to be perceived negatively; in this sense, the work can also be described as "face threatening" for the copy-editor.

There are clear parallels between copy-editing translations and the revision of scholarly texts. Research on politeness and the revision of scholarly texts also underlines the potential sensitivity of the task due to "writers' intellectual and emotional investment in the documents they have created" (Mackiewicz \& Riley, 2003, p. 83).

\section{Presentation of the Findings}

\section{Good practice}

Many Norwegian copy-editors and translators base their practice on a 37-page booklet (Øye, 2011), which was edited by the Norwegian Association of Literary Translators (NO), titled Manusvask i praksis (Copy-editing in practice). The association's members automatically receive this publication, and it is also common for publishing editors to send it to beginners. It is therefore the best available source of information regarding what is generally deemed to be good practice in the Norwegian publishing context. The booklet advises copy-editors working electronically to delete what they believe should be removed from the text and to replace it with new text. Suggestions, questions, remarks and commentaries should, according to the booklet, be written as comments (Øye, 2011, p. 21). Copy-editors are also explicitly advised to avoid superfluous changes, question marks with no explanation or comment and condescending comments/exclamation marks in the margin, all of which reflect that the authors of the booklet are aware of the potential for face damage in the copy-editing process; this is in line with most handbooks for copy-editors (e.g. Einsohn, 2000, p. 44; Sharpe \& Gunther 2009, pp. 77-102). As Tables 1 and 2 show, and as I will further elaborate 
below, the copy-editors of the textual material I have analysed are in line with the above recommendation, as they present many of the potential changes as comments. As we shall see, the comments are also polite.

Independently of what is found in handbooks on copy-editing, the very fact that the material for this study was regarded by the professionals themselves as conflict-free indicates that in terms of politeness, it may in itself be taken as an example and source of knowledge about good practice. It is practice that did not lead to severe face damage for the parties involved.

\section{Number of proposed changes and comments in the translation}

In the nine translations in the material, the number of words that the copy-editors changed was between 0.06 (approximately one word every 16 pages) and 2.35 per standard page of 2,000 characters, as shown in Table 1 . These were changes made directly in the text, with tracked changes, making the changes visible to the translator. ${ }^{7}$

Table 1. Quantitative overview of changes proposed by copy-editors in the translations

\begin{tabular}{|c|c|c|c|c|}
\hline & $\begin{array}{l}\text { Words changed in } \\
\text { body text }\end{array}$ & $\begin{array}{l}\text { Average words } \\
\text { changed per page } \\
\text { of } 2,000 \\
\text { characters }\end{array}$ & $\begin{array}{l}\text { Comments in } \\
\text { body text }\end{array}$ & $\begin{array}{l}\text { Average } \\
\text { comments per } \\
\text { page of } 2,000 \\
\text { characters }\end{array}$ \\
\hline ENG1 & 224 & 0.64 & 49 & 0.14 \\
\hline ENG2 & 281 & 2.35 & 99 & 0.83 \\
\hline ENG3 & 82 & 0.24 & 121 & 0.35 \\
\hline ENG4 & 442 & 0.91 & 66 & 0.14 \\
\hline ENG5 & 105 & 0.41 & 87 & 0.34 \\
\hline ROM1 & 24 & 0.06 & 66 & 0.17 \\
\hline ROM2 & 276 & 0.99 & 85 & 0.30 \\
\hline ROM3a & 28 & 0.15 & 34 & 0.18 \\
\hline ROM3b & 19 & 0.09 & 60 & 0.37 \\
\hline Average & 165 & 0.81 & 74 & 0.32 \\
\hline
\end{tabular}

The changes recorded in the table include typos, punctuation and logical errors, such as confusing the name of one character with that of another (seen in ROM1), as well as minor

\footnotetext{
7 The books vary in genre: ENG1 is a young adult fantasy book; ENG2 is a prize-winning book for young adults; ENG3 is a ladies' novel; ENG4 and ENG5 are crime novels; ROM1 is a crime novel; ROM2 is a prize-winning novel for adults; and ROM3a and ROM3b are classics from the $19^{\text {th }}$ century. As I will show later, the same person copy-edited ROM1, ROM3a and ROM3b, and ROM3a and ROM3b had the same translator. Moreover, the copy-editor of ENG5 was also the same person as the translator of ENG2. Otherwise, there were different translators and copy-editors involved.
} 
stylistic changes such as slightly altering the word order of a sentence (seen, for example, in ENG1).

The number of words that were changed in the translations seems much lower than one might have expected, which was corroborated by most of the copy-editors' claims in the interviews or conversations, that these were good translations that required little intervention, and by the translators' claims in the interviews that they had generally been happy with the work of the copy-editors.

In addition to the use of tracked changes, the copy-editors also used comments. As shown in Table 1 , the number of comments ranged from 0.14 (approximately one comment every seven pages) to 0.83 (almost 1 comment) per standard page of 2,000 characters in the present material. These are "milder" changes in the sense that they are less invasive in the text and may include alternative words or phrases, but this space is also typically used for more serious aspects, for example, when the copy-editor has found text that has been left untranslated or instances where the copy-editor interprets the source text in a different way than the translator and sees the need to explain how and why. Copy-editors' frequent use of comments can be regarded as polite, as they avoid invading the translator's text and leave the final decision to the translator. Jannike, an experienced copy-editor who has not copyedited any of the works in my material, but who works in the same sector, explains:

I would rather make 100 comments too many than one too few. I hope they are useful. That is sort of the contract. And most translators understand this perfectly, and they actually think it is good. So the key word is respect, respect for each other's professions. (Jannike, recorded interview)

\section{Six kinds of comments}

In order to differentiate between different kinds of comments, I divided them into six categories: strong suggestion, explanation, weak suggestion, dialogue, praise and talk. The first three categories represent comments from the copy-editor to the translator in which changes are proposed. The order goes from more to less direct: in the first case (strong suggestion), the copy-editors straightforwardly propose a change, with no hedging or explanation. Doing so in the comments is, however, less invasive and therefore more polite than writing their change directly into the text with tracked changes. In the second case (explanation), the copy-editor proposes a change and explains the reason, making it clear that the change is not superfluous or unmotivated. This way, the copy-editor also makes it possible for the translator to disagree and explain - whether mentally, to him or herself or to the publishing editor if there is a need to discuss it with someone - why they disagree. In the third and least invasive case (weak suggestion), the copy-editor expresses either ostensible or genuine uncertainty, underlining that it is up to the translator to choose.

All changes made in the comments rather than directly in the text can be seen as a way of limiting the face threat towards the translator. Rather than questioning their personal or professional competence (quality or social identity face) directly by imposing their own interpretation in matters that are clearly open to different interpretations and individual judgement, they propose alternatives, explain the reasoning behind their weak suggestions or indicate once more that they are only suggesting. ${ }^{8}$

As presented in Table 2, the findings show that the majority of translators (ENG3, ENG4, ENG5, ROM3a and ROM3b) received a preponderance of weak suggestions, which is the most indirect way of commenting. Even though a higher degree of indirectness is often assumed to make one more polite (Brown \& Levinson 1983; Mackiewicz 2003), I interpret all six styles as politeness strategies and markers of respect, if only by the fact that these changes were

${ }^{8}$ This is also in line with what copy-editors are advised to do in practical guides to the copy-editing of translations, such as Horguelin and Brunette (1998, p. 44) and Mossop (2014, pp. 192-194). 
proposed in comments rather than being tracked in the text. As I shall further discuss below, it is also possible that the degree of directness depends on the relationship between the copyeditor and the translator and that a higher level of directness can be just as polite if the relationship between the two is fairly equal.

The final three categories - dialogue, praise and talk - represent either translator-initiated dialogue between the translator and the copy-editor or spontaneous comments from the copyeditor to the translator that are not aimed at changing the text (either praise or talk). As we will see below, such comments may play a role in creating a bond between the professionals, making them come across as more considerate (and therefore more polite) towards each other.

The distribution of the total number of changes among these six categories is presented in Table 2. Below the table, the categories are explained in greater detail, and some examples are given.

Table 2. Categorization of the copy-editors' comments

\begin{tabular}{|c|c|c|c|c|c|c|c|}
\hline & $\begin{array}{l}\text { Total } \\
\text { comments }\end{array}$ & $\begin{array}{l}\text { Strong } \\
\text { suggestion }\end{array}$ & Explanation & $\begin{array}{l}\text { Weak } \\
\text { suggestion }\end{array}$ & Dialogue & Praise & Talk \\
\hline ENG1 & 49 & $73 \%$ & $12 \%$ & $14 \%$ & & & \\
\hline ENG2 & 99 & $23 \%$ & $20 \%$ & $12 \%$ & $41 \%$ & & \\
\hline ENG3 & 121 & $1 \%$ & $5 \%$ & $64 \%$ & $29 \%$ & & \\
\hline ENG4 & 66 & $11 \%$ & $23 \%$ & $47 \%$ & $17 \%$ & & \\
\hline ENG5 & 87 & & $7 \%$ & $91 \%$ & & $2 \%$ & \\
\hline ROM1 & 66 & $43 \%$ & $14 \%$ & $41 \%$ & & & $2 \%$ \\
\hline ROM2 & 85 & $1 \%$ & $53 \%$ & $46 \%$ & & & \\
\hline ROM3a & 34 & $21 \%$ & $3 \%$ & $76 \%$ & & & \\
\hline ROM3b & 60 & $23 \%$ & $8 \%$ & $70 \%$ & & & \\
\hline
\end{tabular}

Strong suggestion. The copy-editor proposes an alternative by writing the new word or phrase in a comment without adding anything else. For example, in ENG1, the word "act(ion)" (handlingen) appears in a comment linked to the word "the thing" (tingen) - referring to the only thing a character had ever done - allowing the translator to understand that the copyeditor would rather see the suggested word than the word "thing" in the text, but (presumably) respects that the translator might wish to have it that way and that it is a matter of preference. In ENG2, where some sentences and paragraphs have been forgotten by the translator, the copy-editor writes a note simply stating what is missing and on what page in the source text it can be found, implying that it must be translated when the translator revises her work.

Explanation. The copy-editor explains why she proposes changing something in the text, either a tracked change that has already been made or something that is left intact in the body text. For example, in ROM2, "ninety per cent" has been changed to "90\%" in the text, and the copy-editor writes a comment: "I'm changing this, you have written '75\%' above. And that is correct." 
Weak suggestion. Here, the copy-editor is proposing another solution, albeit less resolute. Either the new word or phrase is written with a question mark after it, as in ENG3 when "fatty" is left unchanged but marked with a comment that says "oiled?", or uncertainty is expressed in other ways, such as "maybe" or "perhaps" preceding the word(s) suggested for replacement. In other words, the copy-editor is explicitly stressing that it is up to the translator to decide. In ENG4, the translator has translated a phrase as "Let go of everything else", and the copy-editor writes in a comment, "Perhaps: 'Forget all the rest'". In a more elaborate example, the copy-editor of ENG5 explicitly evokes the translator's right to choose, despite her weak suggestion:

Not sure if $\mathrm{F}$. ought to say [synonym in a formal register] rather than [word in a less formal register] - I'll leave that to the translator.

Sometimes, explanations and weak suggestions co-occur, in which case, they have been counted as weak suggestions:

[the literal translation from English to Norwegian of "I made a mental note"] does not quite make sense - how about "I reminded myself"?

Likewise, the copy-editor of ROM2 gives a series of explanations, followed by asking the translator "Agree?" which have also been counted as weak suggestions.

In ENG5, ROM2 and ROM3a, the copy-editors refer to a lack of clarity in the source text in explanations prior to their weak suggestions, which is also a way of signalling that they see and respect how the translator has thought even as they encourage him or her to make a bolder or more target-oriented choice. Example, in ENG3:

I can see that it says so in the original, but maybe it could be written differently, for example ...?

Dialogue. In addition, some of the documents contain dialogue between the translator and the copy-editor, which has been initiated by the translator. Such a dialogue may look like this (from ENG2):

Translator: This becomes very pompous in Norwegian.

Copy-editor: It will do $:$

Here, the translator has marked a word in her own translation, and the copy-editor suggests that she should leave it as is.

Praise: One document, ENG5, also contained spontaneous praise of the translation. Here, the copy-editor writes "Funny :-)" and "Well solved!" on two separate occasions. Other copyeditors also praise the translations in other contexts: for example, the copy-editor of ENG3 writes in an introductory comment that there was very little to edit in this text, and when the translator writes a comment explaining her use of certain old-fashioned words, she replies, "I absolutely agree. The conservative language feels absolutely appropriate in this excellent translation." ${ }^{\prime 9}$

Talk: At a given point in ROM1, where the novel mentions a gay author who has "come out of the closet", the copy-editor writes, "TALK: extremely relevant these days, think of the debates on [the iconic Norwegian author] Prøysen that have flared up again these days!" The name of the category "talk" is in fact borrowed from this copy-editor, who uses this word as

\footnotetext{
${ }^{9}$ For sociolinguistic and historical reasons, in Norwegian Bokmål, conservative or old-fashioned language is not restricted to the purely lexical level (such as whether one synonym is chosen over another), but may also affect spelling and morphology in ways that may not be evident to those who are not acquainted with the Norwegian language. Many words can be spelt in several different ways, and what forms are chosen may be both a matter of individual preference and stylistic connotation.
} 
her own meta-linguistic tag for her comments. The comment has nothing to do with the copyediting process at all, and can be interpreted as the copy-editor being friendly with the translator - or "bonding".

\section{Adapting the comment to the addressee}

My analysis of the textual material shows the politeness of copy-editors, changing on average only 0.81 words per page with tracked changes, and making extensive use of comments, on average 0.32 per page, that is, one every three pages, most frequently with indirect suggestions, as shown in Table 1.

The interviews held with the copy-editors confirmed that they are conscious of maintaining a polite tone in order to successfully improve the text, bearing the reaction of the addressee (the translator) in mind. The copy-editor of ENG3 explained:

I usually make suggestions if there are things I wonder about, things you don't understand, words, phrases. (...) You are always present [in the text], because the thing is you need to formulate things in a way that makes it easy to accept, to hit the accept button. (Kira, recorded interview)

The need for a respectful tone was also heavily emphasized by Ingvild, one of the most experienced copy-editors I interviewed. She had worked as a full- or part-time copy-editor for 40 years, and having kept a diary of her work for all those years, she laid claim to having copy-edited or proofread around 1,500 books. She had also copy-edited a good deal of Norwegian-language fiction, and she explicitly stressed that she approached translations with the same respect as if they were an original manuscript by a Norwegian author. This involves understanding that whoever has written a text has a strong emotional attachment to it:

So I tend to think that this is someone's baby, in a way. It's something that they've produced, and all my criticism must be very careful. (...) My job as a copy-editor isn't to impose upon a book what I believe to be right. I am there to make suggestions, to see if there are things that deviate from the overall impression of the text, and point them out. (Ingvild, recorded interview)

As shown in Table 2, the results also reveal some differences in the commenting styles of the individual copy-editors, especially in terms of their use of comments. As mentioned, in five of the nine cases (ENG3, ENG4, ENG5, ROM3a and ROM3b), the copy-editors made preponderantly weak suggestions. Of the four other cases, ENG1 contains a majority of strong suggestions, ENG2 has a relatively even distribution among the three suggestion types, and ROM1 and ROM2 both have a roughly even predominance of strong and weak suggestions.

All the copy-editors come across as polite, and the differences in their styles were probably due to individual preferences or to the closeness of the relationship between them and the translators. Of the above translations, ENG1-5 were all translated by different translators and copy-edited by different copy-editors. Conversely, the four Romance-language translations (ROM1-3b) involved three translators and two copy-editors, with ROM1, ROM3a and ROM3b sharing the same copy-editor (Pipp) and ROM3a and ROM3b sharing the same author, translator and publisher. It is noticeable that of all the copy-editors, Pipp had the lowest degree of textual intervention. She is also described by Hugo, the translator of ROM3a and ROM3b, as someone who edits sparingly, commenting only on what is really necessary (Hugo, recorded interview). However, the contributions she does make are judged to be solid. Having been copy-edited by her before, it was Hugo who proposed to the publishing editor that ROM3a and ROM3b be copy-edited by Pipp. In a separate interview, the publishing editor confirmed that she was chosen both because the translator wanted her and because the editor 
herself was well acquainted with Pipp's qualities as a copy-editor (Caroline, recorded interview).

Pipp's editing style is more indirect in ROM3a and ROM3b compared with ROM1, where her suggestions are typically stronger. Moreover, she does not attempt to explain as much to the translator of ROM3a and ROM3b as she does to the translator of ROM1. This might be explained by the fact that the translator of ROM1 is closer to Pipp in age (hence the direct style and the friendly talk referred to above), while the translator of ROM3a and ROM3b is some years older than her and, more importantly, an award-winning translator with a sterling reputation. When confronted with these results, Pipp was surprised and even amused, whereupon she acknowledged that she probably had a higher degree of awe and respect for this translator (Pipp, recorded interview). This is not to say that she is less polite towards the translator of ROM1; she simply has a more direct and equal relationship with this translator. Her praise of the translation of ROM1 was also noticeable as she proposed a change to the text, something that she perhaps deems as unnecessary in the case of ROM3a and ROM3b:

... or something like that. The sentence is not optimal the way it is. I mean - when everything else is so incredibly good! (Pipp, ROM1)

Other copy-editors explicitly acknowledged that they copy-edit differently when the translator is a prize-winning veteran. If the translator is a novice, they will present greater resistance than in the case of an experienced translator who can be expected to know the routines of copy-editing, especially if the translator is award-winning (Eveline, recorded interview; Kira, recorded interview).

Conversely, some veteran translators actually complain about copy-editors intervening insufficiently in their translations. Lina, a translator with 40 years of experience, has noticed that many copy-editors have either too much trust in her competence, leading them to do a sloppy copy-editing job, or too much respect to comment on certain things. This implies extra work for her when going through the copy-edited version of her own translation, where she needs to revise her own text heavily against the original because the copy-editor has not been sufficiently thorough (Lina, recorded interview).

Finally, translator-initiated dialogue, which also makes the translator present in the text, seems to be valued by some copy-editors. When the copy-editor of ENG3 was shown the manuscript at the beginning of the interview, she spontaneously said:

Yes, do you know, this one was incredible - I remember it well, I thought it was so conscientiously translated. Very ... it almost distinguished itself by its very humble comments to the copy-editor, here I have thought this and that, what do you think? ... and it's a really positive thing, I think, if everyone managed to see it like a collaboration about getting the best possible literature regardless of the type. (Kira, recorded interview)

Indirectly, however, Kira's words do show that not all translators appear humble or collaborative in the eyes of the copy-editor. She almost seems surprised that the translator is friendly and present in the text that she has received.

\section{Negative experiences}

My insights into the practices that induce negative reactions from translators and copy-editors were mainly derived from the interviews. Generally speaking, the translators recalled instances in which they had reacted negatively to irony (Cara, recorded interview) and unnecessary changes (Arngrim, recorded interview; Cara, recorded interview), which the abovementioned booklet from the Norwegian Association of Literary Translators recommends that copy-editors avoid. One informant had been particularly unhappy to find a sad emoticon 
among the copy-editor's comments (Johanne, recorded interview). Another aspect that causes special annoyance among translators is copy-editors introducing errors into the translation in the editing process (Cara recorded interview; Oskar, recorded interview). However, as we shall see, several copy-editors had reacted to a harsh or superior tone from translators, especially at the beginning of their career, an aspect to which they drew equal attention as among the most negative aspects of their working conditions, which include their (relatively low) remuneration.

Finding the right tone seems to be part of the professionalization process for copy-editors. Some copy-editors also reported that they had learnt the craft by trial and error. This was the case for Eveline. Upon completing her studies in languages, she sent her résumé to several publishers, offering her services as a translator and copy-editor. When she was given her first job as a copy-editor, she did not get any instructions regarding how the job ought to be done:

The first time, I received a book to copy-edit, they just said, "Maybe you could have a go at this one." So I just did it by intuition. (Eveline, recorded interview)

The first time around, there were no complaints, but her second or third copy-editing job seemed to have been perceived as offensive by the translator:

I have learnt from my own mistakes. (...) Several [people] have been offended and angry. (...) That's probably one of the most important things I have changed since, that I have put myself to one side. (...) Now I have much more respect for translators. (...) In the beginning I was a lot more arrogant. Even though I am better at my work now, I have become more attentive. (Eveline, recorded interview)

Arngrim has also learnt the hard way to find the right tone:

I have to admit that I've made foolish mistakes as a copy-editor. I have been too headstrong and a little bit categorical, especially in the beginning. (Arngrim, recorded interview)

Arngrim recalled his worst experience when he copy-edited the work of a translator he knew personally:

I was a bit disrespectful in my tone and pointed out a bunch of errors. And this was completely taken in the wrong way by the recipient. So it became this whole conflict. Unfortunately. And that was not my intention. I spent an entire Easter holiday trying to write this apologetic letter to account for why I had done what I did. (...) But - that - I don't do it anymore. I thought that the tone I had used was okay precisely because I knew the translator. But it was not okay. (Arngrim, recorded interview)

This has had an impact on how Arngrim revises his own copy-editing before sending it off:

I read the text once, then I always go through my comments afterwards, before sending them, because I need to moderate my comments a little bit. (...) I can probably be a bit too (...) categorical in my comments, so I always need to go back and moderate and tone them down afterwards. Because what instantaneously fires you up, you know, two or three days later, it's no longer so serious. It's like a cooling down period. (Arngrim, recorded interview)

The fact that something "fires you up" as a copy-editor might be related to the solitary working situation of the editing process, where communication takes place as removed correspondence rather than in an ordinary dialogue setting with both parties present at the same time. Indeed, Arngrim, in another context, described the translator and the copy-editor as sitting on different islands. When asked why he enjoys copy-editing, he replied: 
Of course, it improves the text. It raises the text, as some say. Weeding out the mistakes, really. You hear about translators who talk so warmly about this or that copyeditor, a particular copy-editor with whom they have a close and good relationship that raises the text, and so on. I have no experience of this. My experience is of everyone sitting on their own island, or of everyone being a different satellite working in isolation from the others, most of the time. Regardless of the rate, I probably work a bit quicker when copy-editing now than I used to in the beginning. (Arngrim, recorded interview)

This general experience strongly contrasts Kira's acknowledgement of feeling present in the text in ENG3 (see section 5.1).

On the other hand, translators may themselves employ a harsh tone towards copy-editors when they are not happy with their work, as in Eveline (recorded interview) or Kira's experiences. Kira recalled:

A couple of times, I received a cover letter with the assignment, that is, through the publishing house, from a translator who was very grumpy, saying that he was tired of copy-editors who were trying to do his job over again, and this manuscript has been translated and should not be translated again, and a bit between the lines: I have thought through everything, so, yeah, just back off. (...) And, yes, then you proceed in $a$, in a different way. ('Kira', recorded interview)

Copy-editors may also react to translators riding their hobby horses, such as marked spelling that they insist on using. This may make a lasting impression, as explained by Ingvild:

Ingvild: And then, if I know that there is a translator who has strong feelings about $X X$, $X X$ and $X X$ [i.e. words with contested or variant spellings] or other special words, then of course I don't touch them.

Me: But then you must know the translator pretty well to remember?

Ingvild: Well, things like writing $X X$ and $X X$ and so on, I never forget [laughter]. (Ingvild, recorded interview)

The secret to Ingvild's success, though, is that she keeps her mildly negative perceptions of these spellings to herself. Even though they are found in texts in which she personally regards them as non-standard or unsuitable. Translators are happy with her because they know that she will never interfere with spelling that they feel strongly about, whatever her opinion of these words as an individual.

As we have seen, the job of the copy-editor is to check and complement the translator, and many aspiring translators practice as copy-editors before actually translating. To some, it may therefore cause annoyance when translators have done a careless job:

When you have read as many manuscripts as I have, then... And that was also part of the reason why I soon [after becoming a copy-editor] started to think that I would like to translate, because, in a way, with the worst manuscripts, I have almost been thinking that it would have been easier and definitely better if I could have translated them from scratch. (...) So I have always thought, I suppose, the publishing editor at least scrolls through and gets an impression of how much it was, but (...) I think it is a bit strange because you would think that translators get commissions based on the work they have handed in before. (Kira, recorded interview)

Of course, it should not be inferred that Kira has ever copy-edited a manuscript in a way the translator perceived as offensive. Rather, her account may serve to explain why other copyeditors in similar situations could end up expressing their aggression on paper - and not delete it after a "cooling down period", as recommended by Arngrim. 
The feeling that the other party has done a substandard, unprofessional job is also what causes the strongest feeling of aggression among translators, especially, as mentioned above, if copy-editors introduce errors into the translation. This is how Oskar, who has 20 years of experience as a translator, describes the likelihood of a swift erosion of trust in the copyeditor:

It is absolutely terrible. It ruins the whole process. Because when you receive the copyedited text, you have kind of spent the time you had, you don't have more than the allotted time. (...) In the end, you understand that [the copy-editor] is wrong. But then you have maybe spent five minutes, you know, looking things up. Maybe it doesn't sound like much, but in that moment, when you realize he's wrong, you just get furious and then the whole process is ruined, and everything he points out after that is like, "Fuck!" I remember being so angry that I was crossing out [changes that were perhaps justified]. (Oskar, recorded interview)

Oskar recalled informing the copy-editor, whom he knew, about his frustration in this case, and according to Oskar, the copy-editor apologized and referred to unhappy circumstances in his private life that might have impaired his attentiveness as a copy-editor.

Copy-editors such as Eveline and Arngrim reported that they had learnt how to find the "right tone" from trial and error, which had made them more competent as copy-editors. However, another negative aspect reported by the copy-editors, especially the less established ones, were the working conditions. Kira (recorded interview) used to work as a freelance full-time copy-editor, but due to the low pay and unforeseeable workload, she now practiced copyediting in evenings as a "hobby" and combined it with a safe day job in a private company. Another inexperienced copy-editor, Stella (who had several years of experience from the publishing sector as an author), believed that publishers consistently hired inexperienced copy-editors because of the low pay:

You know, the wages are too low. (...) [This is why you get] such a high turnover. Of course, this was just a casual job for me, you know. Obviously, you want better and more experienced editors than me, and to get them, or I mean, to get me in 20 years, as someone who has spent their life editing, then ... But you will never get that because of the low pay. (...) I think you would get a higher quality if the pay were higher. (...) I have spoken to many [people] about this. Many people say this. (Stella and Emma, recorded interview)

The translators participating in this study all worked according to the same standard contract, which (as of 2014) remunerated them with roughly 20 EUR per 1,000 characters regardless of the genre and source language of the translation. Conversely, according to my interviews, the rates that copy-editors get vary tremendously. Publishing editors agree that the rates are probably perceived as low by some of the copy-editors, who seem to have to work quickly, although publishing editors have the freedom to pay a little extra to highly professional, experienced copy-editors who edit difficult texts (Marie, recorded interview; Robert, recorded interview). Some copy-editors who reported that they were paid regularly per 1,000 characters could not remember what the rates were at all, or could only remember how much they could roughly expect to get for a book. Some of them reported that they did not negotiate the rates. Others reported that they did, and some even refused to work as copy-editors if they were not paid at least 350 to 400 NOK per hour (roughly 35 to 45 EUR).

As mentioned earlier, Norwegian literary translators are backed by a strong association. By contrast, few of the literary copy-editors whom I interviewed in 2014 had heard of the Norwegian Copy-editors' Association (Norsk forening for språkkonsulenter). Of those who had heard of it, Eveline reported that the association had not replied to her after she had contacted them. Arngrim knew of them but saw no need to become a member, while Kira had a bad 
conscience because she would have liked to join them out of an idea of solidarity. However, she had not done so because of content on their web page, which gave the impression that they had nothing to offer her. In other words, the level of organization of Norwegian copyeditors is very low compared with both Norwegian translators and the copy-editors of larger countries such as the United Kingdom and Spain, where the respective associations, Society for Editors and Proofreaders and UniCo, are strong and well established. For example, UniCo publishes a yearly white paper on copy-editing (see e.g. UniCo, 2015), a report that contains definitions, figures and statistics intended to cover all aspects of copy-editors' professional situation.

Eveline, an experienced copy-editor who had, at the time of the interview, just been offered her first job as a translator, was quite explicit about the status of copy-editing vis-à-vis translating:

Everything that has a higher status will, of course, be more appreciated. So translation is, in that sense, the more gratifying of the two. Because a copy-editor, even if it's an incredibly important job in that process, is regarded as a toilet emptier. One doesn't have a lot of respect for the copy-editor, one thinks that it is not an important job; then it would have been much better paid. It is a really important job, but it is only perceived as a necessary evil. (Eveline, recorded interview)

In this sense, it seems that the low professionalization of Norwegian copy-editors may also be echoed in the level of appreciation of their work.

The publishing editors also confirmed that publishers are often more in need of copy-editors than translators, since good copy-editors tend to find new jobs after some time. Many newly recruited copy-editors are aspiring translators who have contacted publishers to translate and are offered their first jobs as copy-editors (Marie, recorded interview; Robert, recorded interview). Of course, this is not always the case, and some work as full- or part-time professional copy-editors during their entire working life (such as Ingvild, mentioned above).

As there is almost no formal training for copy-editors in Norway (with the exception of a few university-level courses that were offered for a short time only), publishing editors need to train copy-editors from scratch. This appears to be problematic for publishers:

Marie: This is something that publishing editors complain a lot about - how to find good copy-editors. Also, good copy-editors tend to end up becoming translators after a few years, and then you have to start looking again. (...) We receive many applications, sometimes from people who are absolutely unsuitable.

Me: How do you know who is suitable?

Marie: By looking at their résumé. They have no experience, they are just really good at languages and spelling. That doesn't mean they will do a good job as a copy-editor. Then we have to teach them everything from scratch, and that is very demanding. (Marie, recorded interview)

Finally, this section focuses on the proofreading of ENG3. This document did not constitute part of the quantitative analysis of the above works, precisely because it falls under proofreading, not copy-editing. However, as discussed above, the boundaries between copyediting and proofreading may be blurry. In fact, in this case, contrary to what is conventionally expected, the proofreader had been comparing the translation to its source text to the extent that she had found an entire paragraph that was missing from the translation, which had not been spotted by the copy-editor. As mentioned above, the translator of ENG3 had included a comment to the copy-editor explaining her use of conservative and old-fashioned language, which was justified, as the novel was set in the past. The copy-editor unreservedly agreed with the translator's choices and praised them throughout the novel. However, the translator's 
comments had been deleted by the time the manuscript reached the proofreader, and the translator was annoyed because in the proofread translation, the proofreader had proposed changing stylistic aspects (via tracked changes) that were part of the conservative tone. This, the translator deemed, was outside the proofreader's field of competence, and the translator returned the book to the publishing editor with unflattering comments, such as the following:

No! I have chosen this variant quite consciously, it is grammatically correct and suits the book. A proofreader is in no position to correct such a thing!

It is interesting that the translator, in handing the translation drafts over to me, attached importance to the fact that the proofreader had commented on stylistic aspects (something she perceived as being outside this professional's responsibility) and only later came to think of the missing paragraph (which was strictly speaking not the proofreader's responsibility, but nonetheless highly appreciated by the translator). As it was not addressed to the proofreader, but rather sent to the publishing editor as a means of explaining why some proposed changes had been ignored, it is possible that the feedback quoted above was never conveyed to the proofreader - even though the proofreader could potentially have learned something from it.

\section{Discussion and concluding remarks}

The textual material analysed in this article, which reflected processes in which the level of conflict was low, suggests that experienced copy-editors are very polite, changing only what they deem necessary in the translator's text and adapting both politeness strategies and editing practice to the needs of the particular translator for whom they are editing. Nevertheless, the negative accounts reveal that most translators, copy-editors and publishing editors have experienced instances of higher levels of conflict. The copy-editing process may be understood as an activity type (Levinson, 1979), a specific kind of social activity in which all players are aware that conflicts between parties are latent in the process and that they are "accidents" of the game that occurs from time to time, which is due to the inherent threat to the social identity face of both translators and copy-editors in the copy-editing process and the potential rivalry between translators and copy-editors. At the same time, this awareness influences their "interpretative frames", that is, the body of knowledge that is evoked in order to understand what is to be inferred from utterances (Levinson, 1983, p. 281). In other words, the understanding that experienced players have of how the game may evolve will influence their linguistic behaviour. Copy-editors are aware that they cannot impose upon translators and that translators may react negatively if they do not show due respect to the right of the latter to decide. This awareness seems to be part of their acquired "communicative competence" (Levinson, 1979), which they need to be successful in their profession.

The accounts of anger and frustration related to negative experiences (by both copy-editors and translators) confirm that both parties invest strong feelings in their work. Both translators and copy-editors may react emotionally if the other party comes across as incompetent or disrespectful of their work. The emotional aspect seems to be further accentuated by the solitary nature of the work, whereby the parties seem to be "working from different islands", as there is a considerable time lapse between the moment in which the copy-editor formulates his or her comments and when these comments are received by the translators. Copy-editors thus have an interest in phrasing comments in a way that is easy for the translator to accept. As Kira points out, the copy-editor and the translator, by way of their comments, are present in the text that the other parties receive, and it seems that comments in which the parties address each other directly, such as those classified in this study as dialogue, praise and talk, may function as politeness strategies, in the sense that they create a bond between the professionals. 
This study also shows that many Norwegian copy-editors learn the craft the hard way, through trial and error, as well as in a context of latent rivalry whereby the parties involved will not always pay a novice copy-editor much respect, as reflected in a copy-editor, such as Eveline, who struggles to find the right tone in her comments to translators. Practitioners who have considerable experience in the publishing sector acquire implicit knowledge about the editing process, which novices have to learn by guessing. If inexperienced copy-editors, in general, had the benefit of formal training, and thus had a clearer impression of what is expected of them from the inception, such uncomfortable experiences could perhaps be avoided, not only for the sake of the copy-editor but also for that of the translator. It also seems to be problematic that many copy-editors give up once they have "learnt the game" and their communicative competence (together with their technical skills as copy-editors) is in place, moving onto other professional activities. As explained by Stella earlier, due to the working conditions, some copy-editors even give up before they have become fully experienced.

The incident with the proofreader of ENG3, who came across in a negative manner because she had acted like a copy-editor, suggests that there are specific expectations attached to different roles in the process, conformity to which might benefit the players. However, the incident also suggests that not all parties may necessarily share the same understanding of the delimitations of their role. There could therefore be benefits in having a more explicit role division and better systems of feedback between translators, copy-editors and publishing editors.

Finally, the interviewees I talked to were divided as to the merits of the Norwegian term for copy-editor, whether språkvasker or manusvasker (i.e. 'language cleaner' or 'manuscript cleaner'): Some thought that it was a good metaphor for the work of the copy-editor, whereas others thought that it lowered the occupation's status. Unlike the editorial cachet that is somewhat implied in the corresponding English term "copy-editor", terms such as sprakvasker may easily conjure up the idea of mopping floors and scrubbing linguistic pots and pans, and it is rather surprising that language specialists use this term for their own role and work. This may, in turn, be a consequence of Norwegian copy-editors lacking a strong association that could bring about a concerted change in nomenclature.

On the whole, it seems evident that there is room for improvement in the working conditions, organization and professionalization of Norwegian copy-editors. It is also telling that it is the Norwegian Association of Literary Translators, rather than a copy-editors' association (or a collaboration between the two), that has published the booklet that sets the norms for copyediting in Norway. ${ }^{10}$

Norwegian copy-editors are not mentioned on the copyright page of literary translations. If everything has gone well, they are relegated to invisibility. It is only when some of their justified emendations have been rejected or if they themselves have done a poor job that the attentive reader might be able to detect their absence. According to a Spanish white paper on copy-editing (UniCo 2015, p. 3), though the work of the copy-editor is bound to be invisible - the less you notice it, the better - this does not mean that the profession should be invisible too.

\footnotetext{
${ }^{10}$ This is not to say that only translators have written the book, which had an editorial committee that covered translators (some of whom had experience as copy-editors) and publishing editors.
} 


\section{References}

Braun, V., \& Clarke, V. (2013). Successful qualitative research: A practical guide for beginners. London, England: Sage.

Brown, P., \& Levinson, S. (1987). Politeness: Some universals in language usage. Cambridge, England: Cambridge University Press.

Buzelin, H. (2007). Translations "in the making". In M. Wolf \& A. Fukari (Eds.), Constructing a sociology of translation (pp. 135-169). Amsterdam, the Netherlands: John Benjamins. https://doi.org/10.1075/btl.74.11buz

Culpeper, J. (2011). Impoliteness: Using language to cause offence. Cambridge, England: Cambridge University Press. https://doi.org/10.1017/CB09780511975752

Dam, H. V., \& Koskinen, K. (2016). The translation profession: Centres and peripheries. Introduction. JoSTrans: The Journal of Specialised Translation, 25, 2-14.

Darnton, R. (1982). What is the history of books? Daedalus, 111(3), 65-83.

Einsohn, A. (2000). The copyeditor's handbook: A guide for book publishing and corporate communications. Berkeley, CA: University of California Press.

Fauske, H. (2013). Profesjonsforskningens faser og stridsspørsmål. In A. Molander \& L.I. Terum (Eds.), Profesjonsstudier (pp. 29-53). Oslo: Universitetsforlaget. (Originally published in 2008.)

Foucault, M. (1998). What is an author? (J. V. Harari, Trans.). In J. D. Faubion (Ed.), Aesthetics, method, and epistemology (pp. 205-222). New York: New Press. (Originally published in 1969.)

Goffman, E. (1967). Interaction ritual: Essays on face-to-face behavior. Garden City, NY: Anchor Books.

Jansen, H., \& Wegener, A. (2013). Multiple translationship. In H. Jansen \& A. Wegener (Eds.), Vita traductiva: Vol. 2. Authorial and editorial voices in translation: Collaborative relationships between authors, translators, and performers (pp. 1-42). Montreal, Quebec: Éditions québécoises de l'œuvre.

Kádár, D., \& Haugh, M. (2013). Understanding politeness. Cambridge, England: Cambridge University Press. https://doi.org/10.1017/CBO9781139382717

Lefevere, A. (1992). Translation, rewriting and the manipulation of literary fame. London, England: Routledge.

Levinson, S. C. (1983). Pragmatics. Cambridge: Cambridge University Press.

Levinson, S. C. (1979). Activity types and language. Linguistics, 17, 365-399. https://doi.org/10.1515/ling.1979.17.5-6.365

Love, H. (2002). Attributing authorship: An introduction. Cambridge, England: Cambridge University Press. https://doi.org/10.1017/CBO9780511483165

Mackiewicz, J., \& Riley, K. (2003). The technical editor as a diplomat: Linguistic strategies for balancing clarity and politeness. Technical Communication, 50(1), 83-94.

McGann, J. J. (1992). A critique of modern textual criticism. Chicago, IL: University of Chicago Press.

Molander, A., \& Terum, L. I. (2013). Profesjonsstudier - En introduksjon. In A. Molander \& L. I. Terum (Eds.), Profesjonsstudier (pp. 13-26). Oslo: Universitetsforlaget. (Originally published in 2008.)

Mossop, B. (2014). Editing and revising for translators (3rd ed.). Abingdon, England: Routledge. (Originally published in 2001.)

Øye, A. (Ed.). (2011). Manusvask i praksis. Oslo: Norsk Oversetterforening. 
Parsons, T. (1978). Action theory and the human condition. New York: The Free Press.

Sharpe, L. T., \& Gunther, I. (2009). Editing fact and fiction: A concise guide to book editing. Cambridge, England: Cambridge University Press. (Originally published in 1994.)

Skaaden, H. (2013). Den topartiske tolken. Lærebok i tolking. Oslo: Universitetsforlaget

Spencer-Oatey, H. (2002). Managing rapport in talk: Using rapport sensitive incidents to explore the motivational concerns underlying the management of relations. Journal of Pragmatics, 34, 529-545. https://doi.org/10.1016/S0378-2166(01)00039-X

Stillinger, J. (1991). Multiple authorship and the myth of solitary genius. New York, NY: Oxford University Press.

UniCo (2015). Libro blanco de la corrección. http://www.uniondecorrectores.org/img/web/docs/LibroBlancoCorreccionV2015.pdf

\section{Unpublished Interviews}

Arngrim. Interview by Kristina Solum. Recording. Oslo, 6 October 2014.

Cara. Interview by Kristina Solum. Recording. Oslo, 19 May 2014.

Caroline. Interview by Kristina Solum. Recording. Oslo, 18 November 2014.

Eveline. Interview by Kristina Solum. Recording. Oslo, 25 August 2014.

Hugo. Interview by Kristina Solum. Recording. Oslo, 11 June 2014.

Jannike. Interview by Kristina Solum. Recording. Oslo, 31 October 2014.

Johanne. Interview by Kristina Solum. Recording. Oslo, 16 October 2014.

Kira. Interview by Kristina Solum. Recording. Oslo, 11 November 2014.

Lina. Interview by Kristina Solum. Recording. Oslo, 30 July 2014.

Marie. Interview by Kristina Solum. Recording. Oslo, 13 November 2014.

Oskar. Interview by Kristina Solum. Recording. Oslo, 3 February 2014.

Robert. Interview by Kristina Solum. Recording. Oslo, 23 September 2014.

Pipp. Interview by Kristina Solum. Recording. Oslo, 10 October 2014

Stella and Emma. Interview by Kristina Solum. Recording. Oslo, 11 September 2014. 